Clima e vegetazione

\title{
The Gordon research conference on hydrocarbons and the atmosphere: a great event of science in italy
}

\section{Paolo Ciccioli *}

Citation: Ciccioli P, 2004. The Gordon research conference on hydrocarbons and the atmosphere: a great event of science in italy. Forest@ 1 (1): 12. [online] URL: http://www.sisef.it/

From Sunday 2 to Friday 7 of May 2004 has been held at il Ciocco, near Barga (Lucca), the 3rd Gordon Research Conference on Biogenic Hydrocarbons and the Atmosphere. It is the first time that such prestigious event in science has been held in Italy. More than 100 participants from all over the world have attended to this Conference (see the photograph). About half of them, were young scientists who have exposed for the first time their work by oral presentations and posters to an international audience. The aim of this and the former Conferences, held in Ventura (U.S.A.) and Oxford (U.K.), was to stimulate discussions and reflections on the mechanisms of production, emission, reaction, transport and deposition of organic compounds emitted from all biogenic sources over the earth. It was organized in 1 hour oral presentations summarizing the present knowledge on selected topics and short oral and poster presentations outlining the innovative aspects of ongoing research through the world. Critical discussions were stimulated by discussion leaders having a specific experience on each one of the selected topics.

A unique aspect of the Gordon Research Conferences is that any type of input can be submitted and discussed through a "brain-storm" procedure free from prejudices and formalities. Particularly welcome are interpretations and new theories on labora- tory and field data that are going to be submitted for publication. Intense discussions have been made during this Conference on the biochemistry of isoprenoids in plants, the extent of atmospheric reactions leading to photochemical pollution and the ecological role played by isoprenoids in driving plant-insect interactions.

Particularly numerous and qualified has been the participation of old and senior Italian scientists. We are particularly indebted to the chairs of this Conference, Dr. Francesco Loreto from Italy and Dr. Alex Guenther from the U.S.A., who have selected our country for this event and to Prof. Thomas Sharkey who first proposed and made it possible the use of Gordon Research Conferences for discussing the role of hydrocarbons in the atmosphere. We are also indebted to the Gordon Society, the US-EPA, the National Science Foundation, the BMBF and the European Commission that have provided funds for this event through the ACCENT, VOCBAS and ISONET. All participants are looking forward to reconvene in 2006 in the U.S.A., where the next Conference will be held.

* Istituto di Metodologie Chimiche - CNR, Area della ricerca di Montelibretti (Roma) - email: paolo.ciccioli@imc.cnr.it 